\title{
Under-recording of hospital bleeding events in UK primary care: a linked Clinical Practice Research Datalink and Hospital Episode Statistics study
}

This article was published in the following Dove Press journal: Clinical Epidemiology

\author{
Laura McDonald ${ }^{1, *}$ \\ Cormac J Sammon ${ }^{2, *}$ \\ Mihail Samnaliev ${ }^{2}$ \\ Sreeram Ramagopalan' \\ 'Centre for Observational Research \\ and Data Sciences, Bristol-Myers \\ Squibb, Uxbridge, UK; ' 2 PHMR, \\ Berkeley Works, London, UK \\ *These authors contributed equally to \\ this work
}

Correspondence: Sreeram Ramagopalan Centre for Observational Research and Data Sciences, Bristol-Myers Squibb, Uxbridge UB8 IDH, UK

Tel +44 I89552 3382

Email Sreeram.Ramagopalan@bms.com
Background: Primary care databases represent a rich source of data for health care research; however, the quality of recording of secondary care events in these databases is uncertain. This study sought to investigate the completeness of recording of hospital admissions for bleeds in primary care records and explore the impact of incomplete recording on estimates of bleeding risk associated with antithrombotic treatment.

Methods: The study population consisted of adults with non-valvular atrial fibrillation who had at least one bleed recorded in either the Clinical Practice Research Datalink (CPRD) or Hospital Episode Statistics (HES) while receiving prescriptions for an oral anticoagulant. The proportion of bleeds recorded in HES that had a corresponding bleed recorded in the subsequent 12 weeks in CPRD was calculated, and factors associated with having a corresponding record were identified. Cox proportional hazards analyses investigating the hazard of subsequent bleeding associated with antithrombotic treatment were carried out using linked CPRD-HES data and using CPRD only data, and the results were compared.

Results: Less than $20 \%$ of the 14,361 bleeds recorded in the HES data had a corresponding bleed coded in the CPRD in the subsequent 12 weeks. This proportion varied by bleed characteristics, calendar time, day of week of admission (weekday vs weekend) and oral anticoagulant treatment at the time of the bleed. The hazard of subsequent bleeding associated with vitamin $\mathrm{K}$ antagonists (VKAs) and antiplatelet agents (APAs) relative to no antithrombotic treatment were similar using the linked primary and secondary care dataset (VKA HR ${ }_{\text {adj }} 1.06 \mathrm{CI}_{95}$ 0.96-1.16; APA HR $\mathrm{Hdj} 1.08 \mathrm{CI}_{95} 0.96-1.21$ ) and the unlinked primary care data (VKA HR adj $1.12 \mathrm{CI}_{95}$ 1.01-1.24; APA HR ${ }_{\text {adj }} 1.06 \mathrm{CI}_{95}$ 0.95-1.20).

Conclusion: Secondary care bleeding events are not completely recorded in primary care records and under-recording may be differential with respect to a variety of factors, including antithrombotic treatment. While the impact of under-recording on estimates of the comparative safety of antithrombotic drugs was limited, the extent of the under-recording suggests its potential impact should be considered, and ideally evaluated in future studies utilizing standalone primary care data.

Keywords: real-world data, data linkage, comparative effectiveness, secondary care, atrial fibrillation

\section{Background}

Within the UK National Health Service (NHS), services which typically act as the first point of contact with the health care system are referred to as "primary care" and include general practitioners (GPs), dentists, pharmacists and optometrists. Within 
the NHS, the GP also plays the role of gatekeeper, managing referral to most non-emergency secondary (hospital and community) and tertiary (highly specialized) health care services. As a result, the majority of the UK population are registered with a GP and the GP record is the patient's primary medical record. ${ }^{1}$ In line with this, guidelines indicate that the details of secondary care encounters should be routinely communicated to an individual's GP practice in order to allow for these details to be recorded and ensure continuity of care. ${ }^{2}$ Databases containing data collected in UK primary care have therefore been widely used as a stand-alone resource for research into medical conditions and the drugs used to treat them. ${ }^{3}$

More recently, the linkage of English secondary and primary care datasets has facilitated the conduct of studies exploring the extent to which secondary care events are coded in primary care records. A number of these studies have found coding to be suboptimal, with $17 \%$ of cancers, $34 \%$ of GI bleeds, $21 \%$ of myocardial infarctions, $22 \%$ of poisoning events and $9 \%$ of fractures recorded in the linked dataset not appearing in the primary care record. ${ }^{4-7}$ These results suggest the use of primary care records as a standalone source for research into these conditions is unsuitable and may generate bias.

In order to explore the potential for UK primary care databases to generate real world evidence (RWE) on the safety and effectiveness of antithrombotic treatment, this study investigated the extent to which secondary care bleeds are coded in primary care records among a cohort of individuals with non-valvular atrial fibrillation (NVAF). The study also sought to understand the impact of incomplete recording on estimates of bleeding risk associated with antithrombotic treatment.

\section{Methods}

\section{Data source}

The study was carried out using a linked Clinical Practice Research Datalink (CPRD) - Hospital Episode Statistics (HES) dataset. This dataset combines anonymized medicalrecord data for patients registered with participating GPs in England (the CPRD dataset) with details of their admissions to NHS hospitals (the HES dataset). The linked dataset therefore includes longitudinal information on diagnoses, symptoms, laboratory tests and prescriptions issued by the GP in addition to information on referrals to specialists, hospital admission diagnoses, hospital procedures and deaths. ${ }^{8}$ Clinical events in the CPRD are recorded using the "Read code" clinical coding system. Hospital discharge diagnoses in HES are recorded using the international classification of disease (ICD)-10 clinical coding system. Greater than $98 \%$ of the UK population are registered with a GP and individuals registered with a GP must opt out of data collection in order to be excluded from the CPRD dataset. Despite overrepresenting certain geographical areas of the UK, the CPRD has been found to be representative of the UK population with regard to sex, age and ethnicity. ${ }^{8}$ HES captures information on all NHS hospital admissions occurring in England and on admissions to independent sector providers if funded by the NHS (est. 98-99\% of hospital activity). ${ }^{9}$

\section{Recording of secondary care bleeds in primary care data}

The study population consisted of all adults with a diagnosis of atrial fibrillation recorded in the CPRD or HES who had at least one clinically relevant bleed recorded in either data source between first January 2003 and 31 January 2016 while receiving prescriptions for oral anticoagulant (OAC) treatment. Individuals with codes indicating their atrial fibrillation was valvular were excluded as despite sharing the same electrophysiological abnormality, the differing etiology of this valvular atrial fibrillation warrants the separate consideration of such individuals. Code lists defining atrial fibrillation, valvular conditions and clinically relevant bleeds are provided in the data supplement (Tables 1-6).

Within this population, all clinically relevant bleeding events recorded in the HES and the CPRD were identified using relevant diagnostic codes and classified according to the location in the body in which they occurred (Tables 5 and 6). We refer to "clinically relevant bleeds" to distinguish these from minor bleeds which are non-clinically consequential; such bleeds are not captured by our data source. The proportion of bleeds recorded in HES that had a corresponding record in the CPRD in the subsequent 12 weeks was calculated, overall and stratified by bleed location.

To identify factors associated with a HES bleed having a corresponding bleeding record coded in the CPRD in the

Table I ICD codes used to identify individuals with atrial fibrillation

\begin{tabular}{ll}
\hline ICD I O_code & Diagnosis \\
\hline 148 & Atrial fibrillation and flutter \\
148.0 & Paroxysmal atrial fibrillation \\
148.1 & Persistent atrial fibrillation \\
148.2 & Chronic atrial fibrillation \\
148.3 & Typical atrial flutter \\
148.4 & Atypical atrial flutter \\
148.9 & Atrial fibrillation and atrial flutter, unspecified \\
\hline
\end{tabular}


Table 2 ICD codes used to identify and exclude individuals whose atrial fibrillation was valvular in nature

\begin{tabular}{ll}
\hline ICDIO_code & Diagnosis \\
\hline 105 & Rheumatic mitral valve diseases \\
105.0 & Rheumatic mitral stenosis \\
105.2 & Rheumatic mitral stenosis with insufficiency \\
105.8 & Other rheumatic mitral valve diseases \\
105.9 & Rheumatic mitral valve disease, unspecified \\
108 & Multiple valve diseases \\
108.0 & Disorders of both mitral and aortic valves \\
108.1 & Disorders of both mitral and tricuspid valves \\
108.3 & Combined disorders of mitral, aortic and tricuspid \\
108.8 & valves \\
108.9 & Other multiple valve diseases \\
T82.0 & Multiple valve disease, unspecified \\
T82.6 & Mechanical complication of heart valve prosthesis \\
& Infection and inflammatory reaction due to cardiac \\
T82.8 & valve prosthesis \\
& Other specified complications of cardiac and vascular \\
T82.9 & prosthetic devices, implants and grafts \\
Z95.2 & Unspecified complication of cardiac and vascular \\
Z95.4 & prosthetic device, implant and graft \\
\hline
\end{tabular}

subsequent 12 weeks, generalized estimating equations (GEE) binary regression analysis was performed. The GEE analysis used a binomial distribution, a logit-link and an exchangeable correlation structure to account for the inclusion of repeat bleeds per individual. Bleed characteristics considered in the analysis included OAC treatment at the time of the bleed, bleed type, calendar period, period of week of bleed occurrence (weekday vs weekend). A range of patient characteristics were also considered for inclusion in the model, including age, sex, deprivation (English Index of Multiple Deprivation), ${ }^{10}$ body mass index (BMI), stroke risk factors (history of stroke/TIA, systemic thromboembolism, congestive heart failure, vascular disease, hypertension, diabetes, CHA2DS2-VASc score), bleeding risk factors (bleeding history, liver disease, renal disease, modified HAS-BLED score) and concomitant medical treatment.

\section{Impact of recording completeness on comparative safety of antithrombotic treatment}

In order to further explore the impact under-recording of HES bleeds in primary care data can have on comparative safety and effectiveness analyses, a comparative safety analysis was carried out using two different data sources: a linked CPRD-HES data (linked analysis) and a CPRD only dataset (unlinked analysis). The analysis investigated the impact
Table 3 Read codes used to identify individuals with atrial fibrillation

\begin{tabular}{|c|c|}
\hline Read code & Read term \\
\hline I4AN.00 & $\mathrm{H} / \mathrm{O}$ : atrial fibrillation \\
\hline I4AR.00 & History of atrial flutter \\
\hline 3272.00 & ECG: atrial fibrillation \\
\hline 3273.00 & ECG: atrial flutter \\
\hline $662 S .00$ & Atrial fibrillation monitoring \\
\hline $6 \mathrm{~A} 9 . .00$ & Atrial fibrillation annual review \\
\hline $7,936 \mathrm{~A} 00$ & Implant intravenous pacemaker for atrial fibrillation \\
\hline $793 \mathrm{MI} 00$ & $\begin{array}{l}\text { Percutaneous transluminal ablation of atrial wall for } \\
\text { atrial flutter }\end{array}$ \\
\hline $793 \mathrm{M} 200$ & $\begin{array}{l}\text { Percutaneous transluminal internal cardioversion } \\
\text { NEC }\end{array}$ \\
\hline $793 \mathrm{M} 300$ & $\begin{array}{l}\text { Percutaneous transluminal ablation of conducting } \\
\text { system of heart for atrial flutter NEC }\end{array}$ \\
\hline $8 C M W 200$ & Atrial fibrillation care pathway \\
\hline 8НТу.00 & Referral to atrial fibrillation clinic \\
\hline 8OAD.00 & $\begin{array}{l}\text { Provision of written information about atrial } \\
\text { fibrillation }\end{array}$ \\
\hline $9 \mathrm{hF} . .00$ & $\begin{array}{l}\text { Exception reporting: atrial fibrillation quality } \\
\text { indicators }\end{array}$ \\
\hline $9 \mathrm{hFI} .00$ & $\begin{array}{l}\text { Excepted from atrial fibrillation quality indicators: } \\
\text { informed dissent }\end{array}$ \\
\hline 90 s..00 & Atrial fibrillation monitoring administration \\
\hline 90 s0.00 & Atrial fibrillation monitoring first letter \\
\hline 90 s 1.00 & Atrial fibrillation monitoring second letter \\
\hline $90 s 2.00$ & Atrial fibrillation monitoring third letter \\
\hline $90 s 3.00$ & Atrial fibrillation monitoring verbal invite \\
\hline $90 s 4.00$ & Atrial fibrillation monitoring telephone invite \\
\hline G573.00 & Atrial fibrillation and flutter \\
\hline G573000 & Atrial fibrillation \\
\hline G573100 & Atrial flutter \\
\hline G573200 & Paroxysmal atrial fibrillation \\
\hline G573300 & Non-rheumatic atrial fibrillation \\
\hline G573400 & Permanent atrial fibrillation \\
\hline G573500 & Persistent atrial fibrillation \\
\hline G573600 & Paroxysmal atrial flutter \\
\hline G573z00 & Atrial fibrillation and flutter NOS \\
\hline
\end{tabular}

Abbreviations: ECG, electrocardiogram; NEC, not elsewhere classified; $H / O$, history of; NOS, not otherwise specified.

of using the different data sources on the relative hazard of subsequent bleeding across antithrombotic treatment strategies, within a population of individuals who had suffered a first bleed while using OACs.

For this analysis, the study population consisted of adults with a diagnosis of atrial fibrillation recorded in the CPRD or HES who had a clinically relevant bleed (index bleed) recorded in either data source between 1 January 2003 and 15 March 2012 which occurred while receiving prescriptions for an OAC. Patients were followed from index bleed until the earliest of either 15 March 2012, the date of leaving the database, or the date of death. Prescriptions for vitamin $\mathrm{K}$ antagonists (VKAs) or antiplatelet agents (APAs) issued following the first bleed were identified and used to stratify 
Table 4 Read codes used to identify and exclude individuals whose atrial fibrillation was valvular in nature

\begin{tabular}{ll}
\hline Read code & Read term \\
\hline 7910200 & Prosthetic replacement of mitral valve \\
7910211 & Bjork-Shiley prosthetic replacement of mitral valve \\
7910212 & Bjork-Shiley prosthetic replacement of mitral valve \\
7910213 & Carpentier prosthetic replacement of mitral valve \\
7910214 & Edwards prosthetic replacement of mitral valve \\
7910300 & Replacement of mitral valve NEC \\
7910400 & Mitral valvuloplasty NEC \\
7911200 & Prosthetic replacement of aortic valve \\
7911300 & Replacement of aortic valve NEC \\
7911500 & Transapical aortic valve implantation \\
7911600 & Transluminal aortic valve implantation \\
7914200 & Prosthetic replacement of valve of heart NEC \\
7914211 & Edwards prosthetic replacement of valve of heart \\
7914212 & Starr prosthetic replacement of valve of heart \\
7914300 & Replacement of valve of heart NEC \\
7914600 & Replacement of truncal valve
\end{tabular}

7915000 Revision of plastic repair of mitral valve

$7916000 \quad$ Open mitral valvotomy

$7917000 \quad$ Closed mitral valvotomy

$7919000 \quad$ Percutaneous transluminal mitral valvotomy

$7910.00 \quad$ Plastic repair of mitral valve

7910.11 Mitral valvuloplasty

7910.12 Replacement of mitral valve

7910y00 Other specified plastic repair of mitral valve

$7910 z 00 \quad$ Plastic repair of mitral valve NOS

7911.12 Replacement of aortic valve

7914.II Replacement of unspecified valve of heart

GII..00 Mitral valve diseases

GII0.00 Mitral stenosis

GII2.00 Mitral stenosis with insufficiency

GII2.12 Mitral stenosis with incompetence

GII2.13 Mitral stenosis with regurgitation

GII3.00 Nonrheumatic mitral valve stenosis

GIIz.00 Mitral valve disease NOS

GI3..00 Diseases of mitral and aortic valves

GI30.00 Mitral and aortic stenosis

GI3I.00 Mitral stenosis and aortic insufficiency

GI3I.13 Mitral stenosis and aortic incompetence

GI3I.I4 Mitral stenosis and aortic regurgitation

GI3y.00 Multiple mitral and aortic valve involvement

GI3z.00 Mitral and aortic valve disease NOS

G540z00 Mitral valve disorders NOS

G544.00 Multiple valve diseases

G544100 Disorders of both mitral and tricuspid valves

G544200 Combined disorders of mitral, aortic and tricuspid valves

G544X00 Multiple valve disease, unspecified

Gyul000 [X]Other mitral valve diseases

Gyu5500 [X]Other nonrheumatic mitral valve disorders

Gyu5D00 [X]Multiple valve disorders/diseases CE

P65..00 Congenital mitral stenosis

P650.00 Congenital mitral stenosis, unspecified

P65z.00 Congenital mitral stenosis NOS

SP00200 Mechanical complication of heart valve prosthesis

SyuK6II [X]Embolism from prosthetic heart valve

TB0I200 Implant of heart valve prosthesis + complication, no blame

ZV43300 [V]Has artificial heart valve

$\mathrm{ZV} 45 \mathrm{H} 00 \quad[\mathrm{~V}]$ Presence of prosthetic heart valve

ZVu6e00 [X]Presence of other heart valve replacement

Notes: [V] Supplementary factors influencing health status or contact with health services other than for illness (ICD). $[X]$ Terms which have been added to the Read Codes in order to ensure that every ICD-10 code is cross-mapped to from a Read Code.

Abbreviations: NEC, not elsewhere classified; NOS, not otherwise specified. each individuals' follow-up time into one of three antithrombotic treatment groups: VKA treatment, APA treatment, no antithrombotic treatment. Gaps in treatment of up to 60 days between two prescriptions from the same treatment group were considered to constitute continuous treatment. Cox proportional hazard regression models were used to compare the hazard of subsequent bleeding events across treatment groups in each population, including treatment group as a time varying covariate and controlling for the same patient and bleed characteristics outlined for the GEE analysis above. Hazard ratios are reported along with Wald 95\% confidence intervals.

All analyses were carried out in [SAS/STAT] software (SAS Institute Inc., Cary, NC, USA).

\section{Results}

A total of 14,361 bleeds recorded in HES were identified among patients with NVAF receiving OAC treatment between 2003 and 2016. The proportion of HES bleeds with a corresponding bleed recorded in the CPRD increased from $12.5 \%$ in the first week following the HES bleed to $19.6 \%$ after 12 weeks (Table 7). Similar results, stratified by the location of the bleed, are provided in Table 8 . A greater proportion of respiratory, intraarticular and intracranial bleeds had a consistent bleed code recorded in the CPRD within 12 weeks $(30.1 \%, 40.7 \%$ and $39.2 \%$, respectively) compared to bleeds in other locations, including GI bleeds (13.5\%) and intraspinal bleeds (11.6\%).

Patient characteristics in the linked and unlinked datasets are shown in Table 9. The results of the GEE regression model are provided in Table 10. Of the 14,361 bleeds recorded in HES, intracranial bleeds, bleeds resulting in weekend hospital admission, bleeds occurring longer ago, bleeds occurring during OAC treatment and bleeds occurring in individuals without a history of bleeding risk factors were more likely to have a corresponding bleed recorded in the CPRD in the 12 weeks after hospital admission.

After applying inclusion and exclusion criteria, 5,197 individuals were identified for inclusion in the Cox regression analyses using CPRD data only (Figure S1) and 7,063 individuals were identified for inclusion in the analysis using CPRD-HES linked data (Figure S2). On average, the population identified using linked CPRD-HES data was slightly older than the population identified using unlinked data only, and contained a greater proportion of females, individuals more recently diagnosed with NVAF, individuals with a history of stroke and bleeding risk factors and individuals with evidence of active cancer (Table 9). The index bleeds identified in the linked population occurred more recently and were more severe than those in the unlinked population, 
Table 5 ICD codes defining clinically relevant hospital bleeds and their locations

\begin{tabular}{|c|c|c|}
\hline ICD code & Description & Location \\
\hline 185.0 & Esophageal varices with bleeding & $\mathrm{Gl}$ \\
\hline K25.0 & Gastric ulcer, acute with hemorrhage & $\mathrm{Gl}$ \\
\hline $\mathrm{K} 25.2$ & Gastric ulcer, acute with both hemorrhage and perforation & $\mathrm{Gl}$ \\
\hline K25.4 & Gastric ulcer, chronic or unspecified with hemorrhage & $\mathrm{Gl}$ \\
\hline $\mathrm{K} 25.6$ & Chronic or unspecified with both hemorrhage and perforation & $\mathrm{GI}$ \\
\hline $\mathrm{K} 26.0$ & Duodenal ulcer, acute with hemorrhage & $\mathrm{Gl}$ \\
\hline $\mathrm{K} 26.2$ & Duodenal ulcer, acute with both hemorrhage and perforation & $\mathrm{Gl}$ \\
\hline K26.4 & Duodenal ulcer, chronic or unspecified with hemorrhage & $\mathrm{Gl}$ \\
\hline K26.6 & Chronic or unspecified with both hemorrhage and perforation & $\mathrm{Gl}$ \\
\hline K27.0 & Peptic ulcer, acute with hemorrhage & $\mathrm{Gl}$ \\
\hline $\mathrm{K} 27.2$ & Peptic ulcer, acute with both hemorrhage and perforation & $\mathrm{GI}$ \\
\hline $\mathrm{K} 27.4$ & Peptic ulcer, chronic or unspecified with hemorrhage & $\mathrm{GI}$ \\
\hline K27.6 & Chronic or unspecified with both hemorrhage and perforation & $\mathrm{Gl}$ \\
\hline K28.0 & Gastrojejunal ulcer, acute with hemorrhage & $\mathrm{Gl}$ \\
\hline $\mathrm{K} 28.2$ & Acute with both hemorrhage and perforation & $\mathrm{Gl}$ \\
\hline K28.4 & Gastrojejunal ulcer, chronic or unspecified with hemorrhage & $\mathrm{GI}$ \\
\hline $\mathrm{K} 28.6$ & Chronic or unspecified with both hemorrhage and perforation & $\mathrm{GI}$ \\
\hline K29.0 & Acute hemorrhagic gastritis & $\mathrm{Gl}$ \\
\hline K62.5 & Hemorrhage of anus and rectum & $\mathrm{Gl}$ \\
\hline K92.0 & Hematemesis & $\mathrm{Gl}$ \\
\hline K92.I & Melena & $\mathrm{Gl}$ \\
\hline K92.2 & Gastrointestinal hemorrhage, unspecified & $\mathrm{GI}$ \\
\hline 184.1 & Internal hemorrhoids with other complications & $\mathrm{GI}$ \\
\hline 184.3 & External thrombosed hemorrhoids & $\mathrm{Gl}$ \\
\hline 184.4 & External hemorrhoids with other complications & $\mathrm{Gl}$ \\
\hline 184.8 & Unspecified hemorrhoids with other complications & $\mathrm{GI}$ \\
\hline 198.3 & Esophageal varices with bleeding in diseases classified elsewhere & $\mathrm{GI}$ \\
\hline $\mathrm{K} 22.6$ & Gastro-esophageal laceration-hemorrhage syndrome & $\mathrm{GI}$ \\
\hline $\mathrm{K} 31.8$ & Angiodysplasia of stomach and duodenum with hemorrhage & $\mathrm{Gl}$ \\
\hline K55.2 & Angiodysplasia of the colon with bleeding & $\mathrm{Gl}$ \\
\hline K55.8 & Angiodysplasia of the small intestine with hemorrhage & $\mathrm{Gl}$ \\
\hline K57.0 & Diverticulosis of the small intestine with perforation, abscess and bleeding & $\mathrm{Gl}$ \\
\hline K57.I & Diverticulosis of the small intestine without perforation and abscess, with bleeding & $\mathrm{GI}$ \\
\hline K57.2 & Diverticulosis of the colon with perforation, abscess and bleeding & $\mathrm{Gl}$ \\
\hline K57.3 & Diverticulosis of the colon without perforation or abscess, with bleeding & $\mathrm{Gl}$ \\
\hline K57.4 & Diverticular disease of both the small intestine and the large intestine with perforation, abscess and bleeding & GI \\
\hline K57.5 & $\begin{array}{l}\text { Diverticular disease of both the small intestine and the large intestine without perforation or abscess, with } \\
\text { bleeding }\end{array}$ & $\mathrm{Gl}$ \\
\hline K57.8 & Diverticular disease of intestine, part unspecified, with perforation, abscess and bleeding & $\mathrm{Gl}$ \\
\hline K57.9 & Diverticular disease of intestine, part unspecified, without perforation or abscess, with bleeding & $\mathrm{GI}$ \\
\hline 160 & Subarachnoid hemorrhage & IC \\
\hline 160.0 & Subarachnoid hemorrhage from carotid siphon and bifurcation & IC \\
\hline 160.1 & Subarachnoid hemorrhage from middle cerebral artery & IC \\
\hline 160.2 & Subarachnoid hemorrhage from anterior communicating artery & IC \\
\hline 160.3 & Subarachnoid hemorrhage from posterior communicating artery & IC \\
\hline 160.4 & Subarachnoid hemorrhage from basilar artery & IC \\
\hline 160.5 & Subarachnoid hemorrhage from vertebral artery & IC \\
\hline 160.6 & Subarachnoid hemorrhage from other intracranial arteries & IC \\
\hline 160.7 & Subarachnoid hemorrhage from intracranial artery, unspecified & IC \\
\hline 160.8 & Other subarachnoid hemorrhage & IC \\
\hline 160.9 & Subarachnoid hemorrhage, unspecified & IC \\
\hline 161 & Intracerebral hemorrhage & IC \\
\hline 161.0 & Intracerebral hemorrhage in hemisphere, subcortical & IC \\
\hline 161.1 & Intracerebral hemorrhage in hemisphere, cortical & IC \\
\hline 161.2 & Intracerebral hemorrhage in hemisphere, unspecified & IC \\
\hline 161.3 & Intracerebral hemorrhage in brain stem & IC \\
\hline
\end{tabular}


Table 5 (Continued)

\begin{tabular}{|c|c|c|}
\hline ICD code & Description & Location \\
\hline$|6| .4$ & Intracerebral hemorrhage in cerebellum & IC \\
\hline 161.5 & Intracerebral hemorrhage, intraventricular & IC \\
\hline 161.6 & Intracerebral hemorrhage, multiple localized & IC \\
\hline 161.8 & Other intracerebral hemorrhage & IC \\
\hline 161.9 & Intracerebral hemorrhage, unspecified & IC \\
\hline 162 & Other nontraumatic intracranial hemorrhage & IC \\
\hline 162.0 & Subdural hemorrhage (acute) (nontraumatic) & IC \\
\hline 162.1 & Nontraumatic extradural hemorrhage & IC \\
\hline 162.9 & Intracranial hemorrhage (nontraumatic), unspecified & IC \\
\hline 169.0 & Sequelae of subarachnoid hemorrhage & IC \\
\hline 169.1 & Sequelae of intracerebral hemorrhage & IC \\
\hline 169.2 & Sequelae of other nontraumatic intracranial hemorrhage & IC \\
\hline S06.5 & Traumatic subdural hemorrhage & IC \\
\hline S06.6 & Traumatic subarachnoid hemorrhage & IC \\
\hline S06.4 & Epidural hemorrhage & IS \\
\hline G95.I & Vascular myelopathies (including hematomyelia) & IS \\
\hline $\mathrm{H} 2 \mathrm{I} .0$ & Hyphema & 10 \\
\hline $\mathrm{H} 3 \mathrm{I} .4 \mathrm{I}$ & Hemorrhagic choroidal detachment & 10 \\
\hline $\mathrm{H} 35.73$ & Hemorrhagic detachment of retinal pigment epithelium & 10 \\
\hline $\mathrm{H} 44.8 \mathrm{I}$ & Hemophthalmos & 10 \\
\hline $\mathrm{H} 47.02$ & Hemorrhage in optic nerve sheath & 10 \\
\hline H3І.3 & Choroidal hemorrhage and rupture & 10 \\
\hline $\mathrm{H} 35.6$ & Retinal hemorrhage & 10 \\
\hline $\mathrm{H} 43 . \mathrm{I}$ & Vitreous hemorrhage & 10 \\
\hline $\mathrm{H} 45.0$ & Vitreous hemorrhage in diseases classified elsewhere & 10 \\
\hline N42.I & Congestion and hemorrhage of prostate & $\mathrm{U}$ \\
\hline N02 & Recurrent and persistent hematuria & U \\
\hline N02.6 & Recurrent and persistent hematuria, dense deposit disease & $\mathrm{U}$ \\
\hline N02.8 & Recurrent and persistent hematuria, other & $\cup$ \\
\hline N02.9 & Recurrent and persistent hematuria, unspecified & $\cup$ \\
\hline R3I & Unspecified hematuria & $\mathrm{U}$ \\
\hline R3I.0 & Gross hematuria & $U$ \\
\hline R3I.9 & Hematuria, unspecified & $\mathrm{U}$ \\
\hline M25.0 & Hemarthrosis & IA \\
\hline R04 & Hemorrhage from respiratory passages & $\mathrm{R}$ \\
\hline R04.I & Hemorrhage from throat & $\mathrm{R}$ \\
\hline J94.2 & Hemothorax & $\mathrm{R}$ \\
\hline R04.0 & Epistaxis & $\mathrm{R}$ \\
\hline R04.2 & Hemoptysis & $\mathrm{R}$ \\
\hline R04.8 & Hemorrhage from other sites in respiratory passages & $\mathrm{R}$ \\
\hline R04.9 & Hemorrhage from respiratory passages, unspecified & $\mathrm{R}$ \\
\hline 123.0 & Hemopericardium as current complication following acute myocardial infarction & PC \\
\hline 131.2 & Hemopericardium, not elsewhere classified & PC \\
\hline S26.0 & Injury of heart with hemopericardium & PC \\
\hline N83.6 & Hematosalpinx & GYN \\
\hline N85.7 & Hematometra & GYN \\
\hline N89.7 & Hematocolpos & GYN \\
\hline N92.I & Excessive and frequent menstruation with irregular cycle & GYN \\
\hline N93 & Other abnormal uterine and vaginal bleeding & GYN \\
\hline N93.8 & Other specified abnormal uterine and vaginal bleeding & GYN \\
\hline N93.9 & Abnormal uterine and vaginal bleeding, unspecified & GYN \\
\hline N95.0 & Postmenopausal bleeding & GYN \\
\hline D69 & Purpura and other hemorrhagic conditions & CUT \\
\hline 171.3 & Abdominal aortic aneurysm, ruptured & $\mathrm{RP}$ \\
\hline 171.5 & Thoracoabdominal aortic aneurysm, ruptured & RP \\
\hline K66.I & Hemoperitoneum & RP \\
\hline
\end{tabular}

(Continued) 
Table 5 (Continued)

\begin{tabular}{lll}
\hline ICD code & Description & Location \\
\hline HII.3 & Conjunctival hemorrhage & OTH \\
R3I.I & Benign essential microscopic hematuria & OTH \\
H92.2 & Otorrhagia & OTH \\
I7I.I & Thoracic aortic aneurysm, ruptured & OTH \\
I7I.8 & Aortic aneurysm of unspecified site, ruptured & OTH \\
E07.8 & Other specified disorders of thyroid (including hemorrhage of thyroid) & OTH \\
E27.4 & Other and unspecified adrenocortical insufficiency (including adrenal hemorrhage) & OTH \\
M62.2 & Ischemic infarction of muscle (compartment syndrome, non-traumatic) & COMP \\
T79.6 & Traumatic ischemia of muscle (compartment syndrome) & COMP \\
\hline
\end{tabular}

Abbreviations: IC, intracranial bleed; GI, gastrointestinal bleed; IS, intraspinal bleed; IO, intraocular bleed; PC, pericardial bleed; U, urinary bleed; IA, intraarticular bleed; R, respiratory; GYN, gynecological bleed; COMP, compartment syndrome; CUT, cutaneous/subcutaneous hemorrhage; RP, retroperitoneal bleed; OTH, other bleed.

Table 6 Read codes identifying bleeds in the CPRD

\begin{tabular}{|c|c|c|}
\hline Readcode & Description & Location \\
\hline $158 . .12$ & Vaginal bleeding & GYN \\
\hline I6R..00 & Bleeding symptom & OTH \\
\hline 1928.00 & Bleeding gums & GUM \\
\hline 196B.00 & Painful rectal bleeding & $\mathrm{Gl}$ \\
\hline 196C.00 & Painless rectal bleeding & $\mathrm{Gl}$ \\
\hline IC6..00 & Nose bleed symptom & $\mathrm{R}$ \\
\hline IC62.00 & Has nose bleeds - epistaxis & $\mathrm{R}$ \\
\hline IC6Z.00 & Nose bleed symptom NOS & $\mathrm{R}$ \\
\hline 2BB5.00 & $\mathrm{O} / \mathrm{E}$ - retinal haemorrhages & 10 \\
\hline 2BB8.00 & $\mathrm{O} / \mathrm{E}$ - vitreous haemorrhages & 10 \\
\hline 7017000.00 & Evacuation of subdural haematoma & IC \\
\hline 7404.00 & Surgical arrest of bleeding from internal nose & $\mathrm{R}$ \\
\hline F42y.II & Haemorrhage - retinal & 10 \\
\hline$F 42 y 400$ & Subretinal haemorrhage & 10 \\
\hline$F 42 y 500$ & Retinal haemorrhage NOS & 10 \\
\hline F444000 & Hyphaema & 10 \\
\hline F4K 2800 & Vitreous haemorrhage & 10 \\
\hline G60..00 & Subarachnoid haemorrhage & IC \\
\hline G61..00 & Intracerebral haemorrhage & IC \\
\hline G6I..II & $\begin{array}{l}\text { CVA - cerebrovascular accid due to } \\
\text { intracerebral haemorrhage }\end{array}$ & IC \\
\hline G6I..12 & Stroke due to intracerebral haemorrhage & IC \\
\hline G610.00 & Cortical haemorrhage & IC \\
\hline G612.00 & Basal nucleus haemorrhage & IC \\
\hline G613.00 & Cerebellar haemorrhage & IC \\
\hline G617.00 & Intracerebral haemorrhage, intraventricular & IC \\
\hline G6IX000 & $\begin{array}{l}\text { Left sided intracerebral haemorrhage, } \\
\text { unspecified }\end{array}$ & IC \\
\hline G6IXI00 & $\begin{array}{l}\text { Right sided intracerebral haemorrhage, } \\
\text { unspecified }\end{array}$ & IC \\
\hline G6Iz.00 & Intracerebral haemorrhage NOS & IC \\
\hline G62..00 & $\begin{array}{l}\text { Other and unspecified intracranial } \\
\text { haemorrhage }\end{array}$ & IC \\
\hline G620.00 & Extradural haemorrhage - nontraumatic & IC \\
\hline G62I.00 & Subdural haemorrhage - nontraumatic & IC \\
\hline G622.00 & Subdural haematoma - nontraumatic & IC \\
\hline G623.00 & Subdural haemorrhage NOS & IC \\
\hline G62z.00 & Intracranial haemorrhage NOS & IC \\
\hline G850.00 & Oesophageal varices with bleeding & $\mathrm{Gl}$ \\
\hline G8y0.00 & Haemorrhage NOS & OTH \\
\hline
\end{tabular}

(Continued)
Table 6 (Continued)

\begin{tabular}{|c|c|c|}
\hline Readcode & Description & Location \\
\hline Gyu6200 & {$[\mathrm{X}]$ Other intracerebral haemorrhage } & IC \\
\hline 1110100 & Acute gastric ulcer with haemorrhage & GI \\
\hline JII0III & Bleeding acute gastric ulcer & GI \\
\hline $\mathrm{J} 121100$ & Chronic duodenal ulcer with haemorrhage & $\mathrm{Gl}$ \\
\hline $\mathrm{JI2IIII}$ & Bleeding chronic duodenal ulcer & $\mathrm{Gl}$ \\
\hline 130100 & Acute peptic ulcer with haemorrhage & $\mathrm{Gl}$ \\
\hline$J 150000$ & Acute haemorrhagic gastritis & $\mathrm{Gl}$ \\
\hline $\mathrm{J} 510900$ & Bleeding diverticulosis & $\mathrm{Gl}$ \\
\hline J573.00 & Haemorrhage of rectum and anus & $\mathrm{Gl}$ \\
\hline J573.1I & Bleeding PR & GI \\
\hline $\mathrm{J} 573000$ & Rectal haemorrhage & GI \\
\hline J5730II & Rectal bleeding & $\mathrm{Gl}$ \\
\hline $\mathrm{J} 573012$ & PRB - Rectal bleeding & GI \\
\hline J68..00 & Gastrointestinal haemorrhage & $\mathrm{Gl}$ \\
\hline J681.00 & Melaena & $\mathrm{Gl}$ \\
\hline J68z.00 & Gastrointestinal haemorrhage unspecified & $\mathrm{Gl}$ \\
\hline J68z.11 & GIB - Gastrointestinal bleeding & GI \\
\hline $\mathrm{J} 68 \mathrm{z} 000$ & Gastric haemorrhage NOS & $\mathrm{Gl}$ \\
\hline $\mathrm{J} 68 \mathrm{z} 100$ & Intestinal haemorrhage NOS & $\mathrm{Gl}$ \\
\hline $\mathrm{J} 68 \mathrm{z} 200$ & Upper gastrointestinal haemorrhage & $\mathrm{Gl}$ \\
\hline $\mathrm{J} 68 \mathrm{zz} 00$ & Gastrointestinal tract haemorrhage NOS & $\mathrm{Gl}$ \\
\hline K0A2.00 & Recurrent and persistent haematuria & $\mathrm{U}$ \\
\hline KI97.00 & Haematuria & $\mathrm{U}$ \\
\hline KI97000 & Painless haematuria & $\mathrm{U}$ \\
\hline $\mathrm{K} 197100$ & Painful haematuria & $\mathrm{U}$ \\
\hline KI97300 & Frank haematuria & $\mathrm{U}$ \\
\hline $\mathrm{K} 19 \mathrm{y} 400$ & Bleeding from urethra & $\mathrm{U}$ \\
\hline$K|9 y 4| I$ & Urethral bleeding & $\mathrm{U}$ \\
\hline $\mathrm{K} 3 \mathrm{ly} 000$ & Breast haematoma due to nontraumatic cause & OTH \\
\hline K56yllII & Bleeding - vaginal NOS & GYN \\
\hline $\mathrm{K} 56 \mathrm{y} / \mathrm{I} 2$ & BPV - Vaginal bleeding & GYN \\
\hline K5E..00 & Other abnormal uterine and vaginal bleeding & GYN \\
\hline K5E2.00 & Abnormal vaginal bleeding, unspecified & GYN \\
\hline N091.00 & Haemarthrosis & IA \\
\hline N0916II & Haemarthrosis of the knee & IA \\
\hline N09IM00 & Haemarthrosis of knee & IA \\
\hline N09Iz00 & Haemarthrosis NOS & IA \\
\hline R047.00 & [D]Epistaxis & $\mathrm{R}$ \\
\hline R047.II & [D]Nosebleed & $\mathrm{R}$ \\
\hline R063.00 & [D]Haemoptysis & $\mathrm{R}$ \\
\hline
\end{tabular}


Table 6 (Continued)

\begin{tabular}{lll}
\hline Readcode & Description & Location \\
\hline R063100 & [D]Pulmonary haemorrhage NOS & R \\
R063z00 & [D]Haemoptysis NOS & R \\
S62..00 & Cerebral haemorrhage following injury & IC \\
S62..1I & Extradural haemorrhage following injury & IC \\
S62..13 & Subdural haemorrhage following injury & IC \\
S622.00 & Closed traumatic subdural haemorrhage & IC \\
S629.00 & Traumatic subdural haematoma & IC \\
S62A.00 & Traumatic extradural haematoma & IC \\
S63..00 & Other cerebral haemorrhage following injury & IC \\
S780500 & Retroperitoneal haematoma & RP \\
SE...1I & Haematoma with intact skin & CUT \\
SE46.00 & Traumatic haematoma & OTH \\
SE4z.II & Haematoma NOS & OTH \\
SK02.00 & Secondary and recurrent haemorrhage & OTH \\
SK0y.II & Anterior compartment syndrome & COMP \\
SK0y.12 & Compartment syndrome & COMP \\
SK0y700 & Compartment syndrome & COMP \\
SP21.00 & Peri-operative haemorrhage or haematoma & OTH \\
SP21.12 & Haemorrhage - postoperative & OTH \\
\hline Notes: & & OT \\
\hline
\end{tabular}

Notes: [D] diagnosis. [X] Terms which have been added to the Read Codes in order to ensure that every ICD-I0 code is cross-mapped to from a Read Code.

Abbreviations: O/E, on examination; PRB, per-rectal bleeding; PR, per-rectum; NOS, not otherwise specified; BPV, bleeding per vagina; IC, intracranial bleed; GI, gastrointestinal bleed; IS, intraspinal bleed; IO, intraocular bleed; PC, pericardial bleed; $U$, urinary bleed; IA, intraarticular bleed; R, respiratory; GYN, gynecological bleed; COMP, compartment syndrome; CUT, cutaneous/subcutaneous hemorrhage; $\mathrm{RP}$, retroperitoneal bleed; GUM, gum bleed; OTH, other bleed.

Table 7 HES bleeds with a corresponding bleed recorded in the CPRD in the subsequent 12 weeks

\begin{tabular}{|c|c|c|}
\hline $\begin{array}{l}\text { Bleeds in HES } \\
(n=\mid 4,36 I)\end{array}$ & \multicolumn{2}{|c|}{$\begin{array}{l}\text { Corresponding bleed } \\
\text { recorded in CPRD }\end{array}$} \\
\hline \multicolumn{3}{|c|}{ Weeks after bleed } \\
\hline$+I$ (0-7 days $)$ & I,799 & (12.5) \\
\hline+2 (0-14 days) & 2,110 & (14.7) \\
\hline+4 (0-28 days) & 2,372 & (16.5) \\
\hline+6 (0-42 days) & 2,543 & (17.7) \\
\hline+8 (0-56 days) & 2,653 & (18.5) \\
\hline+10 (0-70 days) & 2,748 & $(19.1)$ \\
\hline+12 (0-84 days) & 2,822 & (19.6) \\
\hline
\end{tabular}

Abbreviations: HES, hospital episode statistics; CPRD, Clinical Practice Research Datalink.

with a greater proportion of gastrointestinal and intracranial bleeds identified (Table 9).

Figure 1 shows the cumulative incidence of bleeding in the unlinked primary care data and the linked primary and secondary care dataset. Adjusting for statistically significant differences in the above characteristics across treatment groups within each population, we found that the hazard of subsequent bleeding associated with VKAs and APAs relative to no antithrombotic treatment were $12 \%$ and $6 \%$ higher, respectively, when using the unlinked primary care data
Table 8 HES bleeds with direct, plausible or possible supporting evidence in the CPRD within 12 weeks, by location of HES bleed

\begin{tabular}{|c|c|c|}
\hline \multirow{2}{*}{$\begin{array}{l}\text { Bleeds in HES } \\
\text { Location }\end{array}$} & \multicolumn{2}{|c|}{$\begin{array}{l}\text { Corresponding } \\
\text { bleed recorded } \\
\text { in CPRD N (\%) }\end{array}$} \\
\hline & & \\
\hline Total $(n=|4,36|)$ & 2,822 & $(19.6)$ \\
\hline Intracranial bleed $(n=|, 7| 3)$ & 620 & $(39.2)$ \\
\hline GI bleed $(n=7,797)$ & $|, 05|$ & $(\mid 3.5)$ \\
\hline Intraspinal bleed $(n=43)$ & 5 & $($ (II.6) \\
\hline Intraocular bleed, major $(n=7)$ & $<5$ & $(\mathrm{NR})$ \\
\hline Intraocular bleed, not major $(\mathrm{n}=82)$ & 13 & $(15.8)$ \\
\hline Pericardial bleed $(n<5)$ & $<5$ & $(\mathrm{NR})$ \\
\hline Urinary bleed $(n=2,296)$ & 449 & $(19.6)$ \\
\hline Intraarticular bleed $(n=162)$ & 66 & $(40.7)$ \\
\hline Respiratory bleed, major $(n<5)$ & $<5$ & $(\mathrm{NR})$ \\
\hline Respiratory bleed, not major $(n=1,984)$ & 597 & $(30.1)$ \\
\hline Gynecological bleed $(n<5)$ & $<5$ & $(\mathrm{NR})$ \\
\hline Compartment syndrome $(n=39)$ & 7 & $(17.9)$ \\
\hline Cutaneous/subcutaneous hemorrhage $(n<5)$ & $<5$ & $(\mathrm{NR})$ \\
\hline Retroperitoneal bleed $(n=84)$ & $<5$ & $(\mathrm{NR})$ \\
\hline Intraabdominal retroperitoneal bleed $(n=4 I)$ & 11 & $(26.8)$ \\
\hline Gum bleed $(n<5)$ & $<5$ & (NR) \\
\hline Other bleed $(n=107)$ & $<5$ & (NR) \\
\hline
\end{tabular}

Abbreviations: HES, hospital episode statistics; CPRD, Clinical Practice Research Datalink; Gl, gastrointestinal; NR, not reported.

(VKA HR $_{\text {adj 1.12 }} \mathrm{CI}_{95}$ 1.01-1.24; $\mathrm{APA} \mathrm{HR}_{\text {adj 1.06 }} \mathrm{CI}_{95}$ 0.95-1.20) and were $6 \%$ and $8 \%$ higher, respectively, when using the linked primary and secondary care dataset $\left(\mathrm{VKA} \mathrm{HR}_{\text {adj } 1.06}\right.$ $\mathrm{CI}_{95}$ 0.96-1.16; APA HR ${ }_{\text {adj } 1.08} \mathrm{CI}_{95}$ 0.96-1.21).

\section{Discussion}

This study found that the coding of hospital bleeds in the primary care record was incomplete, with less than $20 \%$ of individuals with an inpatient diagnosis for a bleed having a bleed coded in their primary care record in the subsequent 12 weeks. Moreover, differences with respect to key clinical and demographic characteristics were observed between patients identified from primary care vs linked data. While under-recording was found to be differential with regard to a number of factors, including OAC treatment, the incomplete recording of bleeds in primary care was not found to considerably bias estimates of the risk of bleeding associated with antithrombotic treatment.

The low proportion of secondary care bleeds having a corresponding bleed recorded in primary care indicates that as much as $80 \%$ of such bleeds could be excluded from a study which utilized primary care data only to identify bleeds. Using primary care data alone will therefore result in false-negative misclassification of exposure, outcome and/ or covariate status. The impact of such misclassification is 
Table 9 Patient characteristics in the linked and unlinked datasets used in the Cox regression analyses

\begin{tabular}{|c|c|c|}
\hline & $\begin{array}{l}\text { Linked } \\
\text { CPRD-HES } \\
n=7,063\end{array}$ & $\begin{array}{l}\text { Unlinked } \\
\text { CPRD } \\
n=5,197\end{array}$ \\
\hline Age, mean (SD) & $76.7(9.5)$ & $76.0(9.4)$ \\
\hline Female, \% & 45.9 & 42.2 \\
\hline \multicolumn{3}{|l|}{ NVAF characteristics } \\
\hline NVAF duration (from first AF diagnosis to index bleed) & $24.9(24.2)$ & $29.1(24.1)$ \\
\hline \multicolumn{3}{|l|}{ NVAF duration (categorized), \% } \\
\hline$<3$ months, $\%$ & 19.0 & 8.4 \\
\hline $3-6$ months, $\%$ & 8.4 & 8.0 \\
\hline 6-9 months, \% & 7.1 & 7.7 \\
\hline $9-12$ months, $\%$ & 5.6 & 6.6 \\
\hline$\geq 12$ months, $\%$ & 59.8 & 69.3 \\
\hline Newly diagnosed NVAF (past 12 months), $\%$ & 40.2 & 30.7 \\
\hline Duration of available baseline period (months), mean (SD) & $465(213)$ & $476(208)$ \\
\hline Duration of follow-up period in months, mean (SD) & $59.7(40.7)$ & $56.0(35.9)$ \\
\hline \multicolumn{3}{|l|}{ Index bleed characteristics } \\
\hline \multicolumn{3}{|l|}{ Calendar year of index bleed, \% } \\
\hline $2003-2007$ & 52.3 & 59.0 \\
\hline $2008-2012$ & 47.7 & 41.0 \\
\hline \multicolumn{3}{|l|}{ Site of initial bleed, \% } \\
\hline Gastrointestinal & 39.5 & 29.6 \\
\hline Respiratory & 20.2 & 23.6 \\
\hline Urinary & 20.0 & 23.9 \\
\hline Intracranial & 7.4 & 5.0 \\
\hline Intraocular & 1.7 & 2.3 \\
\hline Gynecological & 1.7 & 2.7 \\
\hline Intraarticular & 1.4 & 1.5 \\
\hline Gum & 0.7 & 1.2 \\
\hline Retroperitoneal & 0.5 & 0 \\
\hline All other bleeds & 7.0 & 10.2 \\
\hline Major bleed, \% & 17.2 & 8.3 \\
\hline \multicolumn{3}{|l|}{ History of bleeding risk factors } \\
\hline Bleeding history/predisposition, \% & 55.1 & 42.2 \\
\hline Liver disease, \% & 1.7 & 0.5 \\
\hline Renal disease, \% & 23.5 & 25.6 \\
\hline Drugs predisposing to bleeding ${ }^{\mathrm{a}}, \%$ & 13.2 & 18.1 \\
\hline Modified HAS-BLED score (0-8), mean (SD) & $3.0(1.1)$ & $2.6(1.2)$ \\
\hline Serum creatinine, mean (SD) & $103.7(52.1)$ & $104.9(51.3)$ \\
\hline Glomerular filtration rate, mean (SD) & $0.34(0.4)$ & $0.34(0.3)$ \\
\hline \multicolumn{3}{|l|}{ History of stroke risk factors } \\
\hline Stroke/TIA, \% & 24.6 & 20.4 \\
\hline Systemic thromboembolism, \% & $\mathrm{I} .4$ & 0.7 \\
\hline Congestive heart failure, $\%$ & 28.2 & 21.8 \\
\hline Vascular diseases, \% & 25.2 & 38.2 \\
\hline Hypertension, \% & 90.0 & 60.9 \\
\hline Diabetes, \% & 16.4 & 15.7 \\
\hline CHAD2 score (0 to 6), mean (SD) & $2.5(1.3)$ & $2.0(1.3)$ \\
\hline CHA2DS2-VASc score $(0-10)$, mean $(S D)$ & $4.1(1.6)$ & $3.7(1.7)$ \\
\hline \multicolumn{3}{|l|}{ Other medical histories } \\
\hline \multicolumn{3}{|l|}{ Smoking status, $\%$} \\
\hline Current & 14.3 & 15.2 \\
\hline Past or never ${ }^{\mathrm{b}}$ & 2.5 & 2.9 \\
\hline Unknown & 84.2 & 83.0 \\
\hline BMI, mean (SD) & $27.4(5.7)$ & $28.1(5.8)$ \\
\hline Underweight, \% & 2.2 & 1.6 \\
\hline Normal, \% & 30.5 & 20.0 \\
\hline Obese, \% & 23.5 & 21.6 \\
\hline Overweight, \% & 35.3 & 25.0 \\
\hline Unknown, \% & 8.5 & 31.8 \\
\hline Weight, mean (SD) & $78.7(18.4)$ & $81.0(19.4)$ \\
\hline Active cancer (current/prior 12 months), \% & 9.6 & 4.9 \\
\hline Falls, \% & 0.1 & 0.2 \\
\hline
\end{tabular}

Notes: aPrescriptions within 90 days prior to index bleed. 'May overlap with current smoker.

Abbreviations: HAS-BLED, hypertension, abnormal renal and liver function, stroke, bleeding, labile INR, elderly, drugs or alcohol; HES, hospital episode statistics; CPRD, Clinical Practice Research Datalink; AF, atrial fibrillation; NVAF, non-valvular atrial fibrillation; BMI, body mass index; TIA, transient ischemic attack. 
A

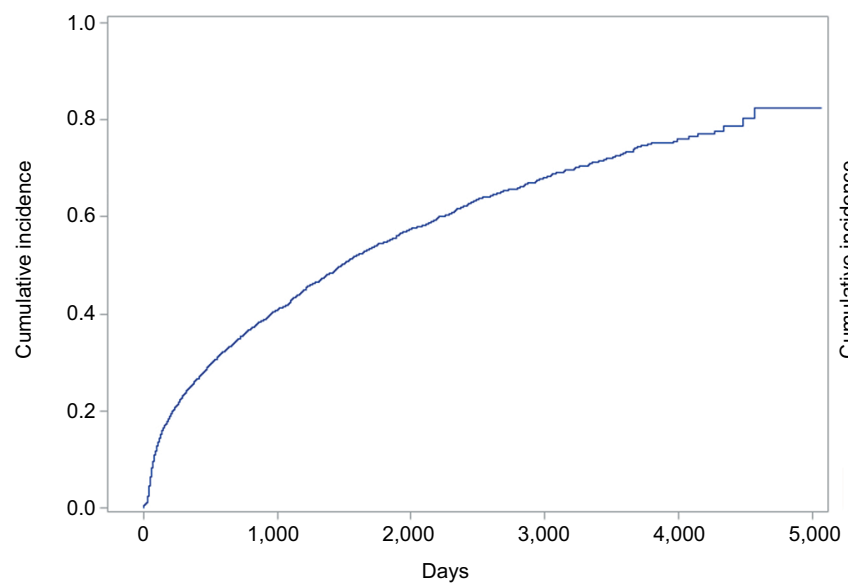

B

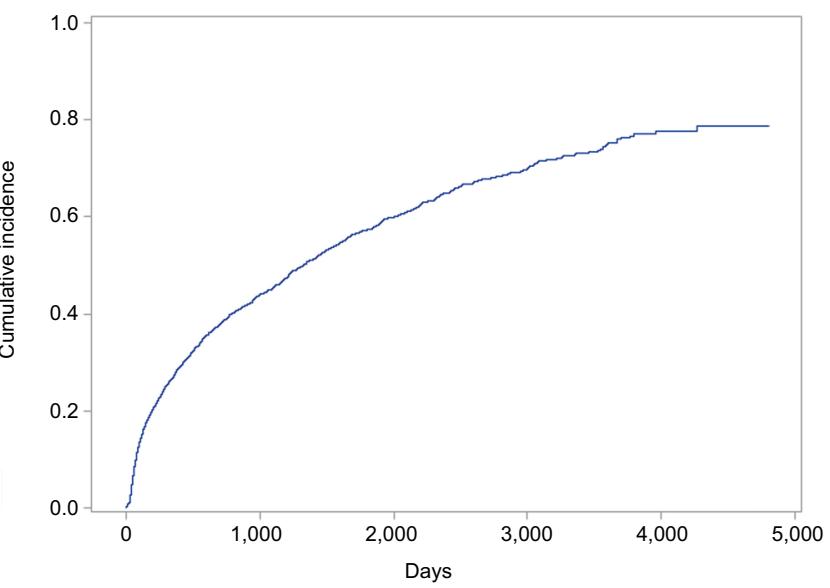

Figure I Cumulative incidence of bleeding in the unlinked primary care data (A) and the linked primary and secondary care dataset (B).

unpredictable and dependent on the study question. While our stratified and GEE analyses suggest that incompleteness varies by a range of factors including OAC treatment, calendar time and bleed location/type, our comparative safety analyses investigating the risk of subsequent bleeding associated with antithrombotic treatment illustrates that for certain study questions the impact on estimates of comparative safety or effectiveness may be small. Despite this, given the extent of under-recording and observed differences in patient characteristics, potential bias introduced through differential misclassification by these and other factors should be taken into consideration in interpreting the results of studies which have used primary care data only to identify bleeds ${ }^{11,12}$ and in the planning of future studies.

Of GP practices contributing to the CPRD, 57\% are eligible for linkage with HES, and no individuals registered with Scottish, Welsh or Northern Irish practices are eligible. ${ }^{13}$ As a result, the use of a HES linked CPRD dataset can have a considerable impact on the generalizability and sample size available for a given study. Given our observation that the impact of under-recording on relative measures of safety or effectiveness can be limited, the decision to use unlinked CPRD vs HES-linked CPRD data must be made on a study specific basis, based on a comparison of the anticipated value that the HES data can add against the reduction in sample size and generalizability it enforces. Based on the extent of underrecording of secondary care bleeding events in primary care data reported here, and the finding that the $\mathrm{HR}$ of subsequent bleeding for VKAs compared to no antithrombotic treatment was slightly higher when using unlinked CPRD data, we suggest that for studies in which bleeding is a key variable, HES linked data is used; at a minimum, to illustrate that findings in the HES-linked data are similar to those in the unlinked data.
Our finding that the odds of a HES bleed having a corresponding CPRD bleed has decreased over time (Table 10) is notable as it suggests that the quality of recording in primary care datasets has decreased over time. This is an interesting finding as it suggests recent efforts to improve and standardize the communication of discharge details between secondary and primary care (eDischarge summaries, ${ }^{2}$ have yet to make an impact. There is a possibility that the decrease in recording over time may represent a change in recording practices rather than a decrease in the quality of recording, as we used specific Read codes related to a bleed in the CPRD to assess consistency with HES data; however, there may have been other Read codes recorded that suggest a bleed occurred (eg, a code for a medical condition for which bleeding is a common symptom). A previous study investigating recording of upper gastrointestinal bleeds in the CPRD and HES included a range of "probable" and "possible" bleed Read codes and found supporting evidence for a much higher percentage of HES bleeds in the CPRD (66\%). ${ }^{5}$ Further, in clinical practice, some Read codes may have "free text" information recorded against them confirming a bleed occurred. These "free text" data consist of unstandardized text which can be used to elaborate on the information contained in the Read code. Free text data are not currently made available for research purposes; however, they are available to individuals involved in the clinical care of patients. While the information contained in related Read codes and the free text may therefore confirm bleeds in some of the cases we have identified, given the magnitude of uncoded secondary care events it is likely that a clinically relevant proportion of individuals did not have their bleed recorded anywhere in their primary care record. These findings are in line with those of a number of studies that have identified shortcomings in communication 
Table 10 Generalized estimating equations (GEE) binary regression analysis investigating factors associated with a HES bleed being recorded in the CPRD

\begin{tabular}{|c|c|c|c|}
\hline Variables & & OR & $95 \% \mathrm{Cl}$ \\
\hline \multirow[t]{2}{*}{ Day of week } & Weekday (reference) & 1 & - \\
\hline & Weekend & 1.25 & $(1.12-1.39)$ \\
\hline \multirow[t]{4}{*}{ Calendar period } & $2003-2005$ & 1.43 & $(1.19-1.71)$ \\
\hline & $2006-2008$ & 1.31 & $(1.12-1.52)$ \\
\hline & $2009-2011$ & 1.09 & $(0.93-1.26)$ \\
\hline & 2012-2016 (reference) & 1 & - \\
\hline \multirow[t]{2}{*}{ OAC treatment at time of index bleed } & No (reference) & 1 & - \\
\hline & Yes & 2.26 & $(1.58-3.23)$ \\
\hline \multirow[t]{6}{*}{ Bleed type } & Intracranial major (reference) & 1 & - \\
\hline & Extracranial major & 0.39 & $(0.32-0.48)$ \\
\hline & GI CRNMB leading to hospitalization & 0.29 & $(0.24-0.35)$ \\
\hline & GI CRNMB not leading to hospitalization & 0.32 & $(0.24-0.43)$ \\
\hline & Other CRNMB leading to hospitalization & 0.44 & $(0.34-0.56)$ \\
\hline & Other CRNMB not leading to hospitalization & 0.48 & $(0.37-0.63)$ \\
\hline \multirow{2}{*}{$\begin{array}{l}\text { History of Gl ulceration, Gl bleeding or } \\
\text { intracranial hemorrhage }\end{array}$} & No (reference) & 1 & - \\
\hline & Yes & 0.75 & $(0.62-0.91)$ \\
\hline
\end{tabular}

Notes: Time since NVAF diagnosis also adjusted for in the analysis.

Abbreviations: HES, hospital episode statistics; CPRD, Clinical Practice Research Datalink; OAC, oral anticoagulant; GI, gastrointestinal; CRNMB, clinically relevant nonmajor bleed; NVAF, non-valvular atrial fibrillation.

during transition of care between secondary and primary care and which have highlighted the safety issues that may result from them. ${ }^{14-21}$ From a research perspective, the unavailability of free text and non-specificity of the "possible" and "probable" codes included by Crooks et al ${ }^{5}$ mean that neither represent feasible approaches to identifying bleeding events in stand-alone primary care data and the high proportions of unreported data we report remain relevant.

The observation that the odds of a HES bleed having a corresponding CPRD bleed is higher for bleeds admitted at the weekend is of interest given the publicity surrounding so-called "weekend effects" in the UK, whereby individuals admitted to hospital at the weekend are more likely to have poor outcomes. It may be possible that admission for bleeds at weekends are more likely to be recorded in the CPRD due to their association with poorer outcomes and therefore being more clinically relevant. Previous methodological work exploring the accuracy of HES data for exploring weekend effects has found that events recorded in HES data on weekdays are more likely to be prevalent events inappropriately recorded as incident events and that this may partly explain the better outcomes observed following these events. ${ }^{22}$ Our finding that HES bleeds admitted on weekdays are less likely to have a corresponding bleed record in the CPRD may therefore reflect the fact that a greater proportion of the weekday admissions are not being recorded by GPs as they are not truly incident bleeds.
Beyond the weekend effect, the potential for inaccurate recording of incident events in HES is an important consideration in interpreting our findings, as thus far we have considered HES to represent a "gold standard" for recording of secondary care events and any events not recorded in the CPRD to represent under-recording in primary care. Inaccuracy in HES coding has been reported previously for a number of event types; however, since the Payment by Results system was introduced in 2004 the average accuracy of coding has been reported to be $96.0 \%$ (interquartile range: $89.3-96.2 \%$ ), $P=0.020) .{ }^{23}$ Notably, this figure has been derived across a range of types of event and most of the studies contributing to this figure focused on the accuracy of ICD coding at the four digit ICD code level. This latter point is important as most of the bleeding ICD codes we have investigated would still have been captured as bleeds had they been miscoded at the four digit level but not at the three digit level. While some of the $80 \%$ of secondary care events not coded in the CPRD may therefore not have been true incident bleeds, we believe it is unlikely that a substantial proportion were. An additional limitation of our study is that it explores only the sensitivity of recording in primary care, but does not explore the specificity. In utilizing the CPRD to investigate bleeding events it is important that the potential for false positive classification of bleeds is given consideration.

A further limitation is that our descriptive analyses do not account for extended hospital stays and deaths. That is, 
$9 \%$ of individuals were not discharged from hospital within the 12 weeks following their index bleed. Such individuals may therefore have supporting evidence recorded later, upon discharge from hospital. Removing undischarged individuals from the denominator has a minimal impact on results, increasing the proportion with supporting evidence recorded to $21.5 \%$. Among the 14,361 individuals with an index bleed, $16 \%$ died during the 12 week follow-up. While individuals who died during the 12 week follow-up do not have the same opportunity to have supporting evidence recorded, this is still notable from a methodological point of view as a study using primary care data may not capture bleeds presenting in secondary care and resulting in deaths within 12 weeks.

\section{Conclusion}

Our results add to the evidence base suggesting secondary care events are not completely recorded in primary care records, and further that under-recording of bleeding events is differential with respect to a variety of factors, including treatment. While the impacts of under-recording on estimates of the comparative safety of antithrombotic drugs obtained from stand-alone primary care data were small, the extent of the under-recording suggests its potential impact should be considered, and ideally evaluated in future studies utilizing stand-alone primary care data.

\section{Disclosure}

SR and LM are full-time employees of Bristol-Myers Squibb, and SR is a shareholder of Bristol-Myers Squibb. CJS and MS are full-time employees of PHMR, PHMR received financial support for the work described in this manuscript from Bristol-Myers Squibb. The authors report no other conflicts of interest in this work.

\section{References}

1. Health and Social Care Information Centre. Attribution Data Set GPRegistered Populations Scaled to ONS Population Estimates - 2011; 2012. Available from: http://www.hscic.gov.uk/catalogue/PUB05054. Accessed January 25, 2018.

2. NHS England» Transfer of Care - eDischarge. Available from: https:// www.england.nhs.uk/digitaltechnology/info-revolution/interoperability/ transfer-of-care-edischarge/. Accessed November 19, 2017.

3. Vezyridis P, Timmons S. Evolution of primary care databases in UK: a scientometric analysis of research output. BMJ Open. 2016;6(10):e012785.

4. Williams R, Gallagher A, van Staa T, Hammad T, Leufkens B, de Vries F. Cancer recording in patients with type 2 diabetes in primary care and hospital admission data. Int J Popul Data Sci. 2017;1(1):314.
5. Crooks CJ, Card TR, West J. Defining upper gastrointestinal bleeding from linked primary and secondary care data and the effect on occurrence and 28 day mortality. BMC Health Serv Res. 2012;12(1):392.

6. Herrett E, Shah AD, Boggon R, et al. Completeness and diagnostic validity of recording acute myocardial infarction events in primary care, hospital care, disease registry, and national mortality records: cohort study. BMJ. 2013;346:f2350.

7. Baker R, Orton E, Tata LJ, Kendrick D. Measurement of the incidence of poisonings, fractures, and burns in children and young people with linked primary and secondary care data: a population-based cohort study. Lancet. 2014;384:S19.

8. Herrett E, Gallagher AM, Bhaskaran K, et al. Data Resource Profile: Clinical Practice Research Datalink (CPRD). Int J Epidemiol. 2015;44(3):827-836.

9. Herbert A, Wijlaars L, Zylbersztejn A, Cromwell D, Hardelid P. Data Resource Profile: Hospital Episode Statistics Admitted Patient Care (HES APC). Int J Epidemiol. 2017;46(4):1093-1093i.

10. The English Indices of Deprivation 2015 - Frequently Asked Questions (FAQs); 2016. Available from: https://assets.publishing.service.gov. uk/government/uploads/system/uploads/attachment_data/file/579151/ English_Indices_of_Deprivation_2015_-_Frequently_Asked_Questions_Dec_2016.pdf. Accessed May 18, 2018.

11. Hollowell J, Ruigómez A, Johansson S, Wallander MA, GarcíaRodríguez LA. The incidence of bleeding complications associated with warfarin treatment in general practice in the United Kingdom. $\mathrm{Br}$ J Gen Pract. 2003;53(489):312-4. Accessed November 30, 2017. http:// pubmedcentralcanada.ca/pmcc/articles/PMC1314574/pdf/12879832. pdf.

12. Scowcroft AC, Lee S, Mant J. Thromboprophylaxis of elderly patients with AF in the UK: an analysis using the General Practice Research Database (GPRD) 2000-2009. Heart. 2013;99(2):127-132.

13. Data Access - CPRD Linked Data. Available from: https://www.cprd. com/dataAccess/linkeddata.asp. Accessed May 18, 2018.

14. van Walraven C, Taljaard M, Bell CM, et al. A prospective cohort study found that provider and information continuity was low after patient discharge from hospital. J Clin Epidemiol. 2010;63(9):1000-1010.

15. van Walraven C, Seth R, Austin PC, Laupacis A. Effect of discharge summary availability during post-discharge visits on hospital readmission. J Gen Intern Med. 2002;17(3):186-192.

16. Bench S, Cornish J, Xyrichis A. Intensive care discharge summaries for general practice staff: a focus group study. $\mathrm{Br} J$ Gen Pract. 2016;66(653):e904-e912.

17. Kripalani S, Lefevre F, Phillips CO, Williams MV, Basaviah P, Baker DW. Deficits in communication and information transfer between hospital-based and primary care physicians. JAMA. 2007;297(8):831.

18. Moore C, Mcginn T, Halm E. Tying up loose ends. Arch Intern Med. 2007; 167(12):1305.

19. Cooper A, Edwards A, Williams H, et al. Sources of unsafe primary care for older adults: a mixed-methods analysis of patient safety incident reports. Age Ageing. 2017;46(5):833-839.

20. Bain A, Nettleship L, Kavanagh S, Babar ZU. Evaluating insulin information provided on discharge summaries in a secondary care hospital in the United Kingdom. J Pharm Policy Pract. 2017;10(1):25.

21. NHS England Patient Safety Domain. Review of National Reporting and Learning System (NRLS) Incident Data Relating to Discharge from Acute and Mental Health Trusts; 2014. Available from: https:// www.england.nhs.uk/wp-content/uploads/2014/08/nrls-summary.pdf. Accessed November 21, 2017.

22. Li L, Rothwell PM; Oxford Vascular Study. Biases in detection of apparent "weekend effect" on outcome with administrative coding data: population based study of stroke. BMJ. 2016;353:i2648.

23. Burns EM, Rigby E, Mamidanna R, et al. Systematic review of discharge coding accuracy. J Public Health. 2012;34(1):138-148. 


\section{Supplementary material}

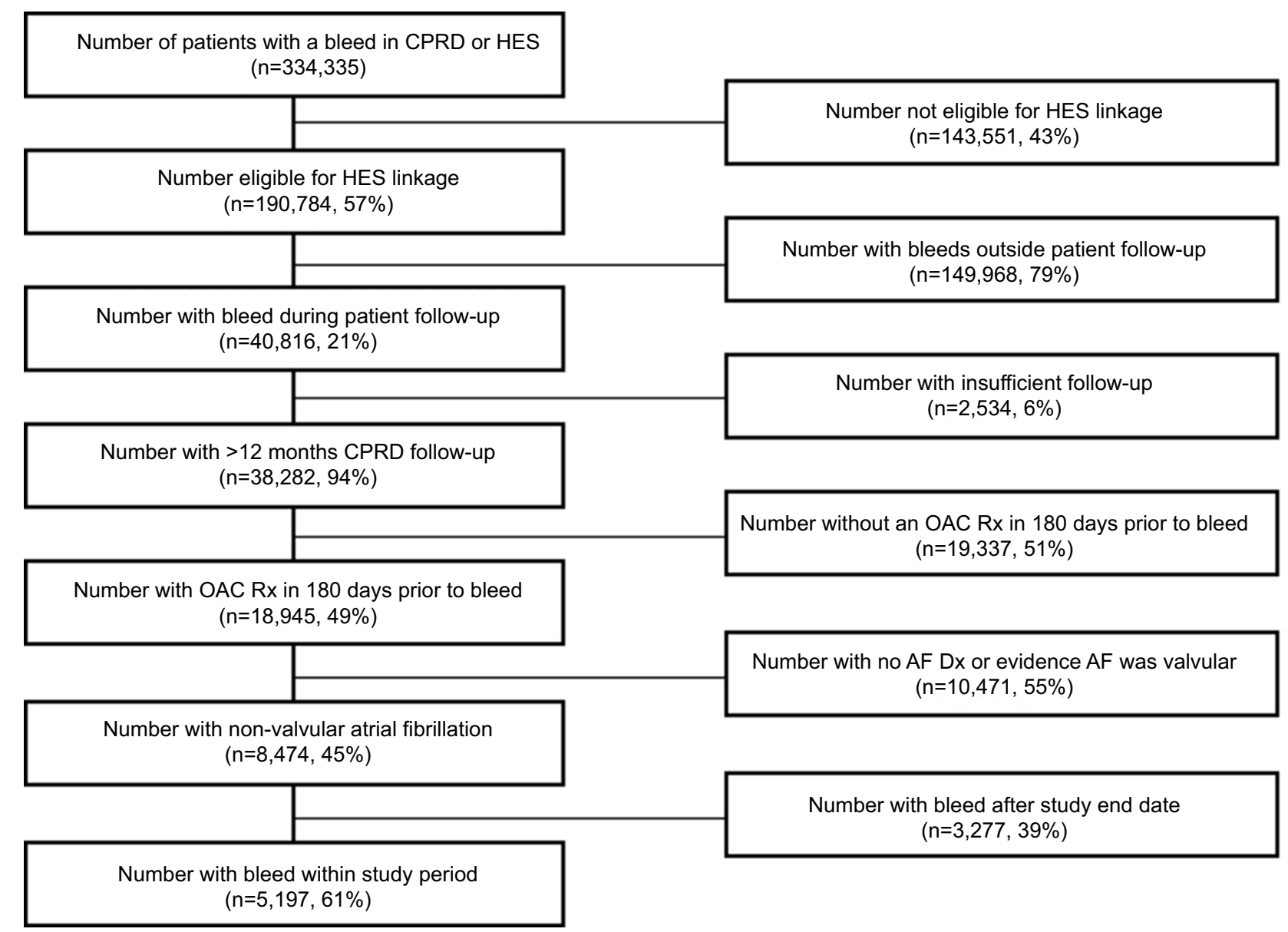

Figure SI Derivation of the study population for the Cox proportional hazards regression analysis using CPRD data only. Percentages shown use the total number of individuals at the next highest level in the flow as their denominator.

Abbreviations: CPRD, Clinical Practice Research Database; HES, hospital episode statistics; OAC, oral anticoagulant; Rx, prescription; Dx, diagnosis. 
Number of patients with a bleed in CPRD or HES $(n=334,335)$

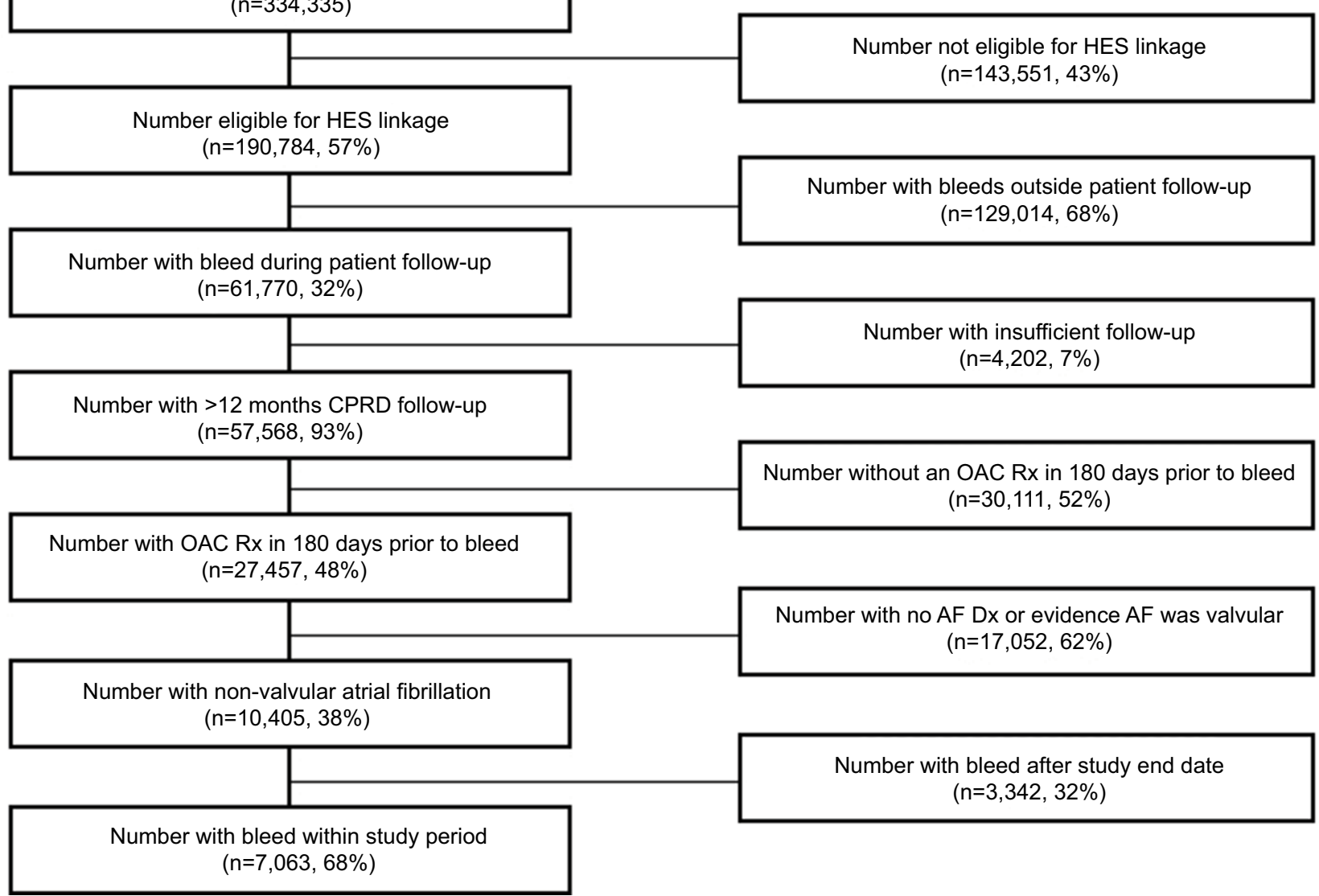

Figure S2 Derivation of the study population for the Cox proportional hazards regression analysis using linked CPRD-HES data. Percentages shown use the total number of individuals at the next highest level in the flow as their denominator.

Abbreviations: CPRD, Clinical Practice Research Database; HES, hospital episode statistics; OAC, oral anticoagulant; Rx, prescription; Dx, diagnosis.

\section{Publish your work in this journal}

Clinical Epidemiology is an international, peer-reviewed, open access, online journal focusing on disease and drug epidemiology, identification of risk factors and screening procedures to develop optimal preventative initiatives and programs. Specific topics include: diagnosis, prognosis, treatment, screening, prevention, risk factor modification,

Submit your manuscript here: https://www.dovepress.com/clinical-epidemiology-journal systematic reviews, risk and safety of medical interventions, epidemiology and biostatistical methods, and evaluation of guidelines, translational medicine, health policies and economic evaluations. The manuscript management system is completely online and includes a very quick and fair peer-review system, which is all easy to use. 